\title{
A Study on Problems in Cooperation, Resource Sharing and Service of University Libraries and Countermeasures
}

\author{
Hui Wang \\ The University of Jinan Library \\ Jinan, China
}

\begin{abstract}
The cooperation between college libraries constantly deepens with the development of librarianship. In the era featuring the rapid growth of sharing economy, how to solve the prominent problems existing in cooperation, resource sharing and service of university libraries is the key and important sally port for the undersupply of resources for building "double first-class" universities. In China, library cooperation service has problems such as unsatisfactory management system and service benefit at the current stage. The cooperation between universities libraries should be improved from the following aspects: provide systematic and feasible countermeasures in terms of cooperative consciousness, personnel training, facility construction and policy incentives, further strengthen the specialization of theoretical study, and raise and deepen the awareness of cooperation and resource sharing between university libraries.
\end{abstract}

Keywords-university libraries; interlibrary cooperation; resource sharing; problems and countermeasures

\section{INTRODUCTION}

The 19th National Congress of the Communist Party of China emphasized that to abundant soul food is a prerequisite to meeting people's new expectation to live a beautiful life. In the new era when sharing economy grows rapidly, how to solve the prominent problems existing in cooperation, resource sharing and service of university libraries is the key and important sally port for the undersupply for building "double first-class" universities.

In the context that university libraries energetically discuss on discipline construction and pay high attention to teaching and scientific research, this article deepens the theoretical study of cooperation, resource sharing and service of university libraries according to contents, models and characteristics of the cooperation between university libraries, that between public libraries and university libraries and that between poverty-stricken areas and university libraries. Meanwhile, this article proposes feasible schemes and countermeasures to promote the cooperation and resource sharing by combining with new characteristics and new theories concerning cooperative development of university libraries, thus allowing university libraries to share information resources and maximizing social and economic benefits.
At first, this article systemizes the problems and progress in library cooperation, resource sharing and service at home and abroad, hoping to better understand the past, seize the future and contribute to the development of cooperative development of university libraries.

II. A COMPARATIVE STUDY OF CHINESE AND FOREIGN LIBRARY COOPERATION, RESOURCE SHARING AND SERVICE IN CURRENT SITUATION

\section{A. Foreign Libraries}

1) A systematic study of theories regarding library cooperation and resource sharing is conducted, which provides the construction of Chinese libraries with references:Theoretical research of cooperative development of libraries started early in foreign countries. In the $1880 \mathrm{~s}$, Library Journal in America started a series of seminars on "Library Cooperation". Simpson clearly proposed the theory of resource sharing in 1990. [1] Afterwards, Prabha and Dannely published a monographic series about resource sharing in 1997 to explain the necessity of library cooperation and key tasks of future development. [3] In 1949, "Center for Research Libraries" co-founded by ten universities in the Midwestern America and the theory of the "Harvard Model" proposed in 1986 became one of the early patterns for the practice and theoretical study of the exploration for cooperative storage. [4]

In addition, Sheng Xingjun dissected domestic and overseas cooperative storage models and introduced three different models-the Harvard Model, the Five Colleges Model and Dutch National Repository and analyzed their advantages in details. [5]Meanwhile, Zhang Haixia and Zhao Boxing analyzed the similarities and characteristics of cooperative storage models in different countries and national conditions, providing the construction of Chinese cooperative storage and shelving system with experience for reference. [6]At present, library storage and shelving system faces two main problems: on the one hand, low utilization ratio of collections; on the other hand, library space in short supply. International development and exploration of library storage and shelving system keeps going. In 1999, 2004 and 2009, Kuopio, Finland, once convoked three international 
conferences specially discussing this issue. [7] The study of cooperative storage of libraries receives high attention from academia. After analyzing the operating mechanism of cooperative storage of libraries of five colleges in America from the perspective of co-governance mechanism of stakeholders, this article argues that co-governance mechanism should be the choice of the governance mechanism for cooperative storage for Chinese libraries in the future. [8]

The theoretical study of library cooperation and resource sharing started earlier in foreign countries, whose social services of libraries are relatively systematic and complete. All cooperative projects are for the purpose of serving the society. For instance, American university libraries have carried out a great number of interuniversity cooperation projects. For example, MIT Libraries Membership Project initiated by the Massachusetts Institute of Technology. [9] SaKai Projects (subprojects under the Stanford University Library) between Stanford University Library and University of Michigan Library, Indiana University Library, UC Berkeley Library and MIT Libraries. Besides interuniversity cooperation, American university libraries also attach great importance to the cooperation with social institutions and international social information organizations. It is because in the information society, the flow of information is precisely the core part of the value of literature. Since 2000, American university libraries have begun to cooperate with international social information organizations and publish new information and new knowledge on the internet with the help of public institutions or private funds, while the information service serves international information demanders. These projects serve developing countries more and provide scholars and non-profit organizations in developing countries with knowledge and resources at a low price or for free. [10]For example, the OARE collaborated by Cornell University Library with the U.S. Environmental Protection Program and private groups is one of the world's biggest databases on environmental science research and is a repository about biology and social sciences; the Harvard University Library's Open Collection Program is instructive and historical resources open to the public and strives to provide scholars and students worldwide with a new model of access to digital resources. The Harvard University Library listed the cooperation as an important part of its 2016-2021 Strategic Plan and put forward the necessity to realize an effective access to global knowledge and data with global cooperation and the use of the internet, the realization of this goal required to prioritize open access and improve the service platform of the libraries. In addition, American university libraries' experience in OA resource building and utilization serves as a guide and reference for Chinese university libraries to construct and utilize OA resources. Foreign university libraries provide the latest research developments and trends regarding library cooperation and resource sharing. The practice of socialized service and relevant systems are relatively mature and perfect. For instance, Cambridge University Library adopts open-shelf service mode that off-campus readers do not need to provide any certificate to enjoy rights other than borrowing books, besides, its chief library, special libraries, academic departments (research centers/institutes) and college libraries are all open to readers outside the university (departments/colleges). Currently, university libraries in countries like America, Japan, Germany, Britain and Australia have socialized their library services to a varying degree. It follows that socialized services offered by university libraries have made a great contribution to knowledge innovation of societies near the universities and life-long education of citizens.

2) A systematic study of the improvement of interlibrary cooperation and resource sharing in the era of new media and the internet is conducted: The use of social media by libraries is at the initial stage in China, while libraries in developed countries have exercised it for a period time. For example, the famous New York Public Library has over 227,630 followers on Twitter and 32,000 fans on Facebook. And these numbers are growing day by day [11]. By incorporating libraries, social media make the platform change from a pure social tool to an integrated platform able to offer authoritative knowledge and information. Besides, at the end of 2004, Google announced its collaboration with five libraries- libraries of University of Michigan, Harvard University, Stanford University and Oxford University and the New York Public Library, in digitalizing their tens of millions of collected books to make these book information retrievable through the internet. [12] Google astonished the library circles with its library cooperation project and made library cooperation and development truly step into the networked new era. The Fourth Sino-American Academic Library Forum for Cooperation in 2017 was the first time that China Academic Social Sciences and Humanities Library (CASHL) went abroad and preliminarily established or deepened the partnership with university libraries like University of Toronto Libraries and University of Michigan Library. [13]

\section{B. Current Situation of Library Cooperation, Resource Sharing and Service of Chinese University Libraries}

Library cooperation and resource sharing among libraries in China started after the establishment of the People's Republic of China. In 1956, the Chinese government issued China's first specialized interlending regulationsInterlending Measures for Institutions of Higher Learning and[14] in 1957, the State Council published the National Plan for Library Coordination. Now, the studies concerning library cooperation conducted by Chinese scholars mostly focus on a specific cooperative project or cooperation mode. Library is a social service agency in nature, and university library owns advanced research results and abundant information resources. Offering social services through library cooperation is a path that must be taken to conform to the development of times and an important way to increase the use rate of university resources and raise social concern.

Cooperative projects of Chinese university libraries include: with the support of China Education and Research Network and Chinese University Library and Information System, the cooperation between Chinese universities made 
a remarkable progress. China Academic Social Sciences and Humanities Library (CASHL for short), China Academic Library \& Information System (CALIS for short) and China Academic Digital Associative Library (CADAL for short) are the well-growing resource sharing projects now. As long as they have the accounts of these centers, users can log in these centers to search the information they need through the access of cooperative universities. The CADAL and the CALIS constitute the framework of the Digital Library for Chinese Higher Education, among which CADAL, as a part of public service system, is a digital library project invested by China and supported by America with people and facility. [15]Some of Chinese university libraries have participated in these three projects, and some of them are the heart of their projects, for instance, Peking University Library and Fudan University Library are the centers of the CASHL. However, the cooperation between domestic university libraries and social organizations is only limited to academic exchange, for example, Zhejiang University Library serves projects like Zhejiang Scientific and Technical Literature Coconstruction and Sharing Platform and Zhejiang Collaborative Online Reference Services; Xi'an Jiaotong University Library has exchanged books and documents with 25 universities and academic societies in 9 countries and regions.

Meanwhile, libraries of Project-211 universities play an important role in the cooperation between Chinese university libraries, especially Project-985 universities. The libraries of these schools become a significant bond between university libraries nationwide in cooperation, such as Tsinghua University Library, National Science Library of Chinese Academy of Sciences, Peking University Library, Zhejiang University Library, Beijing Normal University Library, Library of Xi'an Jiaotong University, Xiamen University Library, Library of Zhejiang University of Technology and Fudan University Library. These university libraries collaborate closely. Besides, there are some special collaborations, such as Tianjin Normal University, Tianjin University Library, Tianjin Polytechnic University Library and Library of Aviation University of China constitute the cooperation between university libraries in Tianjin area, and Hainan Normal University Library, Hainan Medical College Library, University Of Hainan Library and Haikou College of Economics Library constitute the cooperation between university libraries in Hainan. These university libraries rarely communicate with university libraries outside their provinces, but collaborate and communicate with university libraries frequently within their provinces. Cooperation and resource sharing among university libraries in China have made a progress, but the mechanism for library cooperation and resource sharing has not been established yet, so fundamental researches of motives, objectives, pursuits and organization mechanisms of cooperative development become the focus of academic research. Moreover, it is necessary to take creating a good social environment for resource sharing as the impetus for libraries to seek for cooperative development, and amplifying social effect and functions are the ultimate pursuit of cooperative development.

\section{PROBLEMS OF SOME UNIVERSITY LIBRARIES IN COOPERATION, RESOURCE SHARING AND SERVICE}

Accomplishing library cooperation among university libraries is an inexorable trend to materialize resource sharing, develop collections to the maximum extent, meet diversified information demands of students and teachers, and adapt to the development modern information society. But in China, the cooperation between university libraries jogs on.

Some university libraries rarely collaborate with university libraries outside their provinces while collaborate closely with university libraries in their regions. The main reason contributing to this phenomenon is because the cost of cross-regional cooperation among university libraries is higher than that of intra-regional cooperation.

The lack of interlibrary cooperation between Chinese university libraries makes libraries develop sparsely featuring "one library for one university". They still have not broken away from the ideas of "small and comprehensive", "large and comprehensive" and each administers in its own way in terms of the construction of literature resources. Since a single library's power is limited, it is weak in literature collection, technical development and other funding issues, leading to a shortage of funds, a lack of resources purchased and an decrease in the quantity of interblended books on the one hand, on the other hand, a lack of cooperation in hightech projects like digitalization and networked projects causes a huge waste of manpower and materials. This outcome forces libraries to take measures like cutting down books while preserving periodicals, which severally hinders the sustainable development of libraries and slows down literature information resource sharing in China, leading to problems including low rate of resource guarantee, low use rate, repeated construction of resources, lack of overall planning and coordination and non-uniform standards.

\section{FEASIBLE COUNTERMEASURES TO IMPROVE UNIVERSITY LIBRARY COOPERATION, RESOURCE SHARING AND SERVICE}

This article will provide systematic feasible countermeasures in terms of cooperative consciousness, personnel training, faculty construction, approach, policy incentives and so forth.

\section{A. Several Principles to Follow in the Cooperation}

1) Principle of directedness: The first is the use rate of library among readers, namely the breadth and depth of services provided by libraries to readers; the second is outcomes obtained by readers by using the library; then is readers and society's recognition of library and return. Readers dominate the realization of social value of libraries. Library cooperation should be reader-oriented.

2) Principle of equality and mutual benefit: Cooperative libraries are divided into public libraries and university libraries, libraries in impoverished areas and Project-211 university libraries, and large and small libraries, but the 
equality of each library must be stressed. Meanwhile, different libraries have different advantages and characteristics and should stress complementary benefits in cooperation. Only by following the principle of equality and mutual benefit can we fairly and reasonably mediate and solve all kinds of problems and conflicts occurring in cooperation and jointly complete a cooperative project.

3) Principle of shared objective: Any cooperation is generated as driven by a certain objective, as the unification of an overall goal is the foundation of cooperation, so libraries must seek major common points while reserving minor differences in cooperation.

4) Contents needed to be considered in cooperation:

- Personnel. Personnel are the subject of cooperation. Effective communication and cooperation must be conducted among managerial personnel and librarians of different libraries. Managerial personnel have their comprehensive quality improved in cooperation and play the role as a decision supporter and coordinator in cooperation. Libraries jointly develop human resources through collaboration and training.

- Resources. Abundant information resources are the foundation for a library to provide readers with services. The collections of a single library cannot meet the needs of readers, so to maintain resource advantage, it is necessary to co-build and share resources, which is the most important part of the cooperation.

- Organization. As an organizational form of coconstruction and sharing of resources, library consortium is receiving more and more attention from library circles. The task of a consortium is to realize the cooperation in sharing and information service of information resources. For example, co-purchasing eresources, joint virtual reference and consulting service, joint librarian training and continued education and so forth. Alliance cooperation between University libraries takes many forms with different scope, and all that matters is that goal of a consortium is better collaboration.

- Funds. Funds issue is a bottleneck which restrains the development of librarianship. However, library cooperation is a major way to deal with a shortage of funds. For example, libraries that have reached an agreement can negotiate with publishers and database suppliers and lower the prices of electronic information resources by jointly purchasing in the form of a consortium, which saves the expenditure on resource construction. In addition, libraries may offer many forms of paid information services through cooperation to increase their economic income.

- Technology. The development of modern libraries is constantly driven by new technology. It is beyond the reach of a signal library, and it requires concerted effects made by technical sections of libraries as well as the cooperation between library and other related organizations. For instance, the construction of a digital library is not just library's business, and it cannot be done successfully without software developer and hardware producer must.

\section{B. The Following Points Needed to Be Noticed When Developing Library Consortia and Establishing an Organizational Foundation for Each University Library to Cooperate}

It is necessary to establish an authoritative institution, practice macro-control and uniform planning for resource construction, database construction and construction of automatic network of all university libraries, make a development plan for the sharing of literature resource, and determine uniform service standards and principles of resource sharing. Moreover, library consortia at the national level need to realize intersystem cooperation, achieve seamless connection and integration of systems, take a super part of Chinese library consortia, and truly build an information assurance and service system covering all universities across China.

At present, the internet greatly boosts the cooperation between libraries due to the emergence of information network, national library collaboration network is a consortium formed with computer network as the basic platform. They concentrate collecting and editing collection and training on the same platform to realize resource sharing. Then, National Library Cataloging Center is the foundation for integrating cataloguing resources with computer tools and sharing cataloguing resource. For example, realizing coconstruction and sharing of cataloguing data and resources with the National Library as the center can reduce the cost of cataloging.

Library cooperation needs to ensure university libraries can build up special collections different from other university libraries according to their own pattern of literatures and resource advantages. To disparate literature resources are worth sharing. Taking the construction of special collection is the core and coordinating procurement to allow unique and precious literature resources of each university to be allocated more effectively. Moreover, it is necessary to ensure the systematicness and authority of special collections, thus improving the quality of collections to make it convenient for teachers and students to use.

China Academic Library and Information System (CALIS) is a three-tier literature guarantee system. The first tier is CALIS Management Center, which proposes a number of measures to further advance the innovation and reformation of the practices of all university libraries. Located at the Peking University, CALIS Management Center has four national disciplinary literature information centers, which are at Peking University Library, Library of China Agricultural University, Tsinghua University Library and Peking University Health Science Center respectively. The second tiers of CALIS are eight regional literature information centers. They are seven regional literature information service centers in Northeast China, Central China, Southeast China, South China, Northeast China and Southwest China and Northeast National Defense Literature 
Information Service Center. The third tier are provinciallevel centers and all university libraries that have not entered "211" Project.

In summary, we should draw on the operating experience of foreign library consortia (e.g. the model of library cooperation in the network age-ohiolink of America), vigorously develop library cooperation with Chinese characteristics and future advance the sharing of literature resources among university libraries.

\section{A THEORETICAL SUMMARY OF CONSTRUCTION} CONCEPTS AND BASIC GOALS OF COOPERATION, RESOURCE SHARING AND SERVICE OF UNIVERSITY LIBRARIES IN THE NEW ERA

Library cooperation, resource sharing and service needs to strengthen the systematization and specialization of theoretical research to form a complete set of system. And it is necessary to conduct a research and analysis on all fronts including collections fathoming, survey of circulation rate, model building, technical support, and sources of funds. The study of every research field and research content should be careful and thorough to promote the systematization and specialization of the study of library cooperation, resource sharing and service on the whole.

In the context of building "double first-class" universities, to create world-class disciplines and become a world-class university, universities must break down the barriers for academic research and realize the sharing of research resources. More importantly, library should become the model and benchmark for information resources sharing. "You can't have a great university without a great library", said David Jordan, the first president of Stanford University of America. University libraries have always played an important status and role in advancing higher education and social and scientific progress. What world-class universities share in common is their having first-class libraries and firstrate libraries. Because first-class disciplines need first-class talents, first-class management and first-class resource guarantee. While information service is offered by libraries is a part of the resource.

\section{CONCLUSION}

To become world-class universities, Chinese universities must strengthen the building of world-class faculty and concentrate on the needs of students and teachers in terms of information resource construction. Moreover, it is necessary to gain a deep understanding of research direction of each team teacher and organize information resources according to research direction and objective of each teacher in the team. Besides paper literatures, the most important thing for library collection is to strengthen the construction of a database of cutting-edge disciplines, let big data serve disciplines and speed up the building of first-class disciplines. Meanwhile, when acquiring digital information resources, we should pay attention to the source of this literature information and try to maintain the original appearance of this literature. For literature information resources for creating first-class disciplines, the proportion of foreign literatures should be higher than that of domestic literatures. In addition, acquisitioning personnel in libraries need to be fully aware of the current situation, prospects and research trends of building first-class disciplines, and libraries should exert their best efforts to meet the resource demands proposed by discipline teams. Furthermore, it is necessary to further improve librarians' foreign language proficiency and their ability to organize and integrate information resources. Only in this way can we provide knowledge guarantee and intellectual support for universities to create first-class disciplines.

American famous librarian Gorman $G$ summarized the advantages of library cooperation into four aspectsexpanding resources, systematic collection, ensuring special collections and saving expenditure. Conducting library cooperation can effectively enhance the guarantee rate of literature resource of university libraries. College libraries should strengthen library cooperation, intensify resource sharing, and provide students and teachers with superior services. It is necessary to attach importance to "double firstclass" construction and energetically discuss about discipline construction, which is of great importance to teaching and scientific research and personnel assessment for universities.

\section{REFERENCES}

[1] Gao Fan. Thoughts on American Library Consortia [J], Journal of the Library Science Society of Sichuan, 2005(2):72-76.

[2] SLMPSON.DB. Library Consortia and Access To Information: Cost and Cost Justification [J]. Journal of Library Administration, 1990, 12(3):83-97

[3] Hu Jiarong \& Zou Wei. Inspiration for China From the Study of Foreign University Library Consortia $[\mathrm{J}]$. Researches in Library Science, 2008(9):9-12

[4] Basbanes. The Eternal Library: Grit and Fortitude [M]. Translated by Yang Chuanwei, Shanghai: Shanghai People's Publishing House, 2010

[5] Sheng Xingjun. A Study of Foreign Low-Use-Rate Cooperative Literature Storage Mechanisms [J], Library and Information Service, 2010(11):18-21

[6] Zhang Haixia \& Zhao Boxing. A Study of Low-Use-Rate Cooperative Literature Storage Mechanisms [J], Researches in Library Science, 2010(2):86-89

[7] 3rd International Conference on Repository Libraries [EB/OL].[201509-11]. http://www.varastokirjasto.fi/Kupio3/programme.htm

[8] Wang Benxin. Research on Governance Mechanism Adopted by Cooperative Storage Libraries-From Shared Governance's Perspective [J]. Library Tribune, 2013(5): 1-5

[9] Library Services for Outside Users [EB/OL]. (2008-02-14)[2008-0612]. http://Libraries.mit.edu/groups/visitors/programs.html

[10] Yale University Library News [EB/OL]. (2008-05-20)[2008-06-11]. http://www.Library.yale.edu/librarynews/projects/

[11] Chen Wei \& Wang Qiong. A Study of Cooperative Development of Social Media and Libraries [J], Academic Forum, April 4, 2004.

[12] Li Jinhua. A Study of Library Cooperative Development of Libraries [J], Researches in Library Science, Feb. 2011(Application Edition)

[13] Ai Chunhui, Zhu Benjun \& Xiao Long. An Overview of "the Fourth Sino-American Academic Library Forum for Cooperation and Development”. Journal of Academic Libraries, 2017, Issue 4

[14] Peng Renyao. An exploration of FAQ service of Libraries [J], Library Tribune, 2007(3):110 
[15] China Academic Digital Associative Library [EB/OL]. [2008-06-14]. http://www.cadal.zju.edu.cn/Index.action.

[16] Zhang Xinhe \& Xiao Ximing. Innovation Research on Mechanism of Library Collaboration and Information Resource Sharing [J], Library Journal, 2010, Issue 2

[17] Wang Xin. Organization, formation and service of disciplinary knowledge [J], China Modern Educational Equipment, 2014, Issue 11. 